\title{
Researchers' roles in knowledge co-production: experience from sustainability research in Kenya, Switzerland, Bolivia and Nepal
}

\author{
Christian Pohl, Stephan Rist, Anne Zimmermann, Patricia Fry, \\ Ghana S Gurung, Flurina Schneider, Chinwe Ifejika Speranza, \\ Boniface Kiteme, Sébastian Boillat, Elvira Serrano, \\ Gertrude Hirsch Hadorn and Urs Wiesmann
}

\begin{abstract}
Co-production of knowledge between academic and non-academic communities is a prerequisite for research aiming at more sustainable development paths. Sustainability researchers face three challenges in such co-production: (a) addressing power relations; (b) interrelating different perspectives on the issues at stake; and (c) promoting a previously negotiated orientation towards sustainable development. A systematic comparison of four sustainability research projects in Kenya (vulnerability to drought), Switzerland (soil protection), Bolivia and Nepal (conservation vs. development) shows how the researchers intuitively adopted three different roles to face these challenges: the roles of reflective scientist, intermediary, and facilitator of a joint learning process. From this systematized and iterative self-reflection on the roles that a researcher can assume in the indeterminate social space where knowledge is co-produced, we draw conclusions regarding training.
\end{abstract}

$\mathrm{S}$ USTAINABLE DEVELOPMENT requires production of knowledge that strikes a balance between scientific and other forms of knowledge. According to Agenda $21^{1}$ — the action programme resulting from the 1992 United Nations Conference on Environment and Development in Rio - 'the best scientific and traditional knowledge available' (Agenda 21, Ch. 35.5) should be used in knowledge production for sustainable development, and 'methods to link the findings of the established sciences with the indigenous knowledge of different cultures' (Agenda 21, Ch. 35.7) should be developed. This claim challenges the perception of a

Christian Pohl (corresponding author) is at the Department of Environmental Sciences (D-UWIS), CHN H 70.1, ETH Zurich, 8092 Zurich, Switzerland; and at transdisciplinarity-net, Swiss Academies of Arts and Sciences, Schwarztorstrasse 9, 3007 Bern, Switzerland; Email: christian.pohl@env.ethz.ch; Tel: +41 446326310 .

Continued on page 2 . clear-cut border and division of labour between science and society, and the idea that science holds a monopoly over knowledge production. Instead, in sustainability research, critiques of the top-down model of knowledge transfer and patriarchalcolonial paradigm of corresponding capacity building as 'banking concepts' (Freire, 1970), 'deficit models' (Lewenstein, 2002; Wynne, 1991) and 'neocolonial science' (Dahdouh-Guebas et al., 2003) have gained currency. Consequently, increasing attention has been given to interactive ways of producing knowledge, conceived of as a basic requirement in research for sustainable development (Hirsch Hadorn et al., 2008; Rist et al., 2006; Pregernig, 2006; Guggenheim, 2006; Maasen and Lieven, 2006; Robinson and Tansey, 2006; Cundill et al., 2005; Lawrence and Després, 2004; Kasemir et al., 2003; Ravetz, 2001; Klein et al., 2001; Funtowicz et al., 2000).

Recent scholarly discussions have two different ways of conceptualizing the means through which 
Christian Pohl is co-director of transdisciplinarity-net of the Swiss Academies of Arts and Sciences <www. transdisciplinarity.ch> and senior researcher at the Department of Environmental Sciences at ETH Zurich. He was trained in environmental sciences. His main field of interest and publication is the analysis and design of inter- and transdisciplinary research, specifically in the field of sustainability.

Stephan Rist focuses on political ecology, transdisciplinary knowledge co-production, and social learning processes in the context of sustainable governance of natural resources. His empirical research addresses increasingly contested nature-society relationships in European and South American territorialities, focusing in particular on the epistemological, intra- and intercultural implications of the theory and practice of transdisciplinary research for sustainable development.

Anne Zimmermann is a senior research scientist with a background in literatures in English and post-colonial studies; she is associate editor of Mountain Research and Development and coordinates publications and career development for the NCCR North-South. Her current research interest is in conceptual, theoretical and practical aspects of sustainable development research in a North-South context.

Patricia Fry founded the firm 'Knowledge Management Environment' in 2001 to build bridges between science and practice. She uses films and an actor-oriented approach to enhance learning among practitioners, public administration and research. Based on her PhD she initiated and managed the transdisciplinary project 'Farmer to Farmer'. She lectures at the Swiss Federal Institute of Technology (ETH).

Ghana S Gurung is responsible for managing WWF-Nepal's programs and networking with national and international partners, including research institutes. Since 1986, he has been working with rural communities living in protected areas of Nepal. His interest lies in reconciling nature conservation priorities with people's livelihood and development needs.

Flurina Schneider is a geographer and a researcher at the Research Institute of Organic Agriculture. She focuses on processes of knowledge co-creation through social learning and network building in the field of natural resource governance. She has been participating in a number of projects on rural sociology, communication of innovation and trust building, including a COST project.

Chinwe Ifejika Speranza is a geographer and a researcher at the German Development Institute/Deutsches Institut für Entwicklungspolitik (DIE-GDI), Bonn, Germany. Her research focuses on adaptation to climate change in African agriculture. She also teaches adaptation to climate change and soil and water conservation at the DIE-GDI Postgraduate School as well as at its Global Governance School.

Boniface Kiteme is the director of the Centre for Training and Integrated Research in Arid and Semi-Arid Lands Development and Regional Coordinator of the NCCR North-South Programme in East Africa. He is trained in urban and regional planning and his research interest is in water resource management and governance, rural livelihoods and food security, and policy and dissemination.

Sébastien Boillat studied environmental science at the Swiss Federal Institute of Technology in Zurich (ETHZ) and holds a PhD in geography from the University of Bern. His research focused on traditional ecological knowledge, natural resource management and biodiversity. He is currently applying for a post-doc on the transformation of multifunctional rural systems in Latin America.

Elvira Serrano (Msc) is a PhD candidate at the University of Bern (NCCR North-South). She is supervisor of the research program at ADESO in Cochabamba, Bolivia. She also teaches at the Agronomy Faculty of the Universidad Mayor de San Simon. Her main interests are development issues related to ethically based economies, transdisciplinarity, knowledge management, ethical values, and bio-cultures.

Gertrude Hirsch Hadorn joined the Department of Environmental Sciences at ETHZ in 1990. She was president of the transdisciplinarity-net of the Swiss Academies of Arts and Sciences from 2003 to 2008. Her research addresses the philosophy of environmental sciences and sustainability research as well as environmental ethics and ethics of science.

Urs Wiesmann is Professor of Geography at the University of Bern, Director of the Centre for Development and Environment and the NCCR North-South programme, and Visiting Professor, University of Nairobi. His research focuses on human geography, sustainable regional development, natural resource management and global change particularly in developing countries, and inter- and transdisciplinary methodology and application in the context of development and environment.

Gertrude Hirsch Hadorn is also at D-UWIS; Email: hirsch@ env.ethz.ch. Stephan Rist, Anne Zimmermann, Flurina Schneider, Sébastian Boillat and Urs Wiesmann are at the Centre for Development and Environment, University of Bern, Hallerstrasse 10, 3008 Bern, Switzerland; and also work for the NCCR NorthSouth programme; Emails: Stephan.Rist@cde.unibe.ch; Anne.Zimmermann@cde.unibe.ch; flurina.schneider@fibl.org; sboillat@hotmail.com; Urs.Wiesmann@cde.unibe.ch.Patricia Fry is at Knowledge Management Environment, Idaplatz 3, 8003 Zurich, Switzerland; Email; contact@patriciafry.ch. Ghana S Gurung is at WWF Nepal Program, PO Box 7660, Baluwatar, Kathmandu, Nepal; Email: ghana.gurung@wwfnepal.org. Chinwe Ifejika Speranza is at the German Development Institute, Tulpenfeld 6, 53113 Bonn, Germany; Email: Ifejika.Speranza@ die-gdi.de. Boniface Kiteme is at the Centre for Training and Integrated Research in Arid and Semi-arid Lands Development, PO Box 144, Nanyuki, Kenya; Email: b.kiteme@africaonline.co.ke. Elvira Serrano is at the Asociación para el Desarrollo Sostenible (ADESO), Av. Aniceto Arce - Pasaje Olmeto N 2, Cochabamba, Bolivia; Email: adesobolivia@cotas.net. interactive knowledge production takes place. In the first, a new kind of organization is seen as emerging: 'boundary organizations'. Boundary organizations 'exist at the frontier of the two relatively different social worlds of politics and science, but have distinct lines of accountability to each' and 'involve participation of actors from both sides of the boundary, as well as professionals who serve a mediating role' (Guston, 2001: 400-401). Examples of boundary organizations are the US American Office of Technology Assessment and research institutions engaged in adopting El Niño forecasts to regional scales (Cash et al., 2006; Agrawala et al., 2001; Guston, 1999).

In the second type of conceptualization of interactive knowledge production, a new kind of research is said to evolve out of the interaction. Gibbons, Nowotny and colleagues describe it as 'Mode 2 
knowledge production' taking place in the context of application and providing 'socially robust knowledge' (Nowotny et al., 2001; Gibbons et al., 1994). In European sustainability research this understanding has been further developed within the framework of 'transdisciplinary research' (Hirsch Hadorn et al., 2008; Klein et al., 2001). Our understanding of coproduction of knowledge is based on this framework.

These concepts of interactive knowledge production differ in how they conceive of the interaction between 'science' and 'non-science' (Figure 1). In the first case, 'boundary organizations' are defined as belonging neither to the realm of science nor to the realm of politics. They stand in between, thus 'help[ing to] stabilize the boundary between science and politics' (Guston, 1999: 88). In the second case, co-production of knowledge is understood as a collaborative endeavour of academic and non-academic actors (Robinson and Tansey, 2006; Lemos and Morehouse, 2005). This process of knowledge production takes place at the intersection of the realms of science and non-science - the agora - a 'public space in which "science meets the public", and in which the "public speaks back to science", (Nowotny et al., 2001: 247). As a consequence the boundaries between the classical epistemological realms and corresponding roles of academic and non-academic actors are blurred. ${ }^{2}$ In the case of policy-making, for example, the role of science changes from simply providing technical information to the 'much more diffuse activity' of 'assisting in the process of governance' (Funtowicz et al., 2000: 335). Such co-production is seen as consisting of:

highly interactive processes among different researchers and social actors, organized in

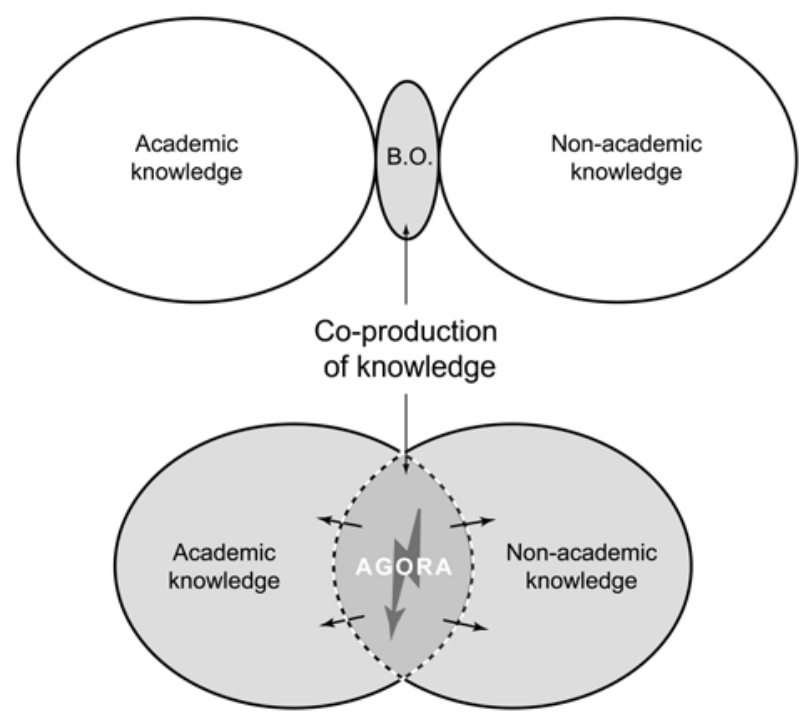

Figure 1. Two approaches to interactive knowledge production: boundary organizations (B.O.) stabilize the boundary between academic and non-academic communities. With co-production of knowledge, both realms are conceived of as overlapping in a permeable space, the agora different phases with changing relationships among social and cognitive components. (Becker, 2003, as quoted in Pregernig, 2006)

Hence, co-production of knowledge interferes with conventional research practices and self-conceptions (as well as roles) of researchers in a fundamental way, and researchers may 'find themselves in a situation of divided identity' (Ravetz, 2001: 391). ${ }^{3}$ How do researchers deal with such situations in the knowledge co-production process? How can they best contribute to this process within the context of research for sustainable development? And how do they succeed in enabling a constructive dialogue between apparently incompatible worlds?

The challenges of dealing with a divided identity as a researcher in a knowledge co-production process are numerous; there is a need to reflect on them in a more systematic manner (Owens et al., 2004) and they need to be addressed at different levels: the levels of theory, practice, training and institutions. The present article explores the first level (theory) through a reflection on concepts relevant to knowledge co-production in sustainability research, and the second level (practice) through a comparative analysis of empirical sustainability research in four different countries; it evokes the third (training) through conclusions drawn from this double reflection on theory and practice. The fourth level (institutions) is beyond the scope of this article.

Our analysis of the challenges that the coproduction of knowledge poses to the researchers, and of the roles in which these challenges are met, proceeds in five steps. First we briefly present our methodology. Second we discuss the specific challenges of co-producing knowledge in sustainability research and define our understanding of the concept of 'roles' in the knowledge co-production process. Third we review four recent research projects in Kenya, Switzerland, Bolivia and Nepal to explore how and in what roles the researchers met the challenges in different problem contexts. These research projects addressed such diverse sustainability issues as vulnerability to drought and food insecurity, implementation of soil protection measures, and the dilemma of conservation versus development. Section four offers a detailed discussion of the roles in which the researchers met the challenges, followed by conclusions that lead into the debate about training issues.

\section{Approach and methods}

We addressed knowledge co-production from a Mode 2 perspective. ${ }^{4}$ Our aim was to analyse the features of co-production of knowledge in and for the context of application (on the basis of case studies). To this purpose we involved two groups of researchers in an iterative, self-reflexive process: (A) researchers experienced in science studies, and (B) researchers conducting sustainable research projects 
and involved in co-production with non-academic actors. Both (A) and (B) co-produced knowledge about challenges met by sustainability researchers and the roles in which these challenges were met, with a view to making the results 'socially robust' in the context of sustainability research.

Our systematic analysis of co-producing knowledge started in spring 2005, when the four projects of sustainability research selected for analysis were close to completion; it ends with the present article. The design of our Mode 2 knowledge productionbased analytical process also used grounded theory (Strauss and Corbin, 1990), the model of participatory action research (Elden and Levin, 1991), and the framework of analytical autoethnography (Anderson, 2006). Hence, our analyses of the specific challenges and roles of sustainability researchers are the result of a collective learning process evolving from increasingly systematic selfreflection, carried out in a continuous iteration between the contextualized experiences of the four projects and a scholarly discussion of Mode 2 types of knowledge production. The path of our learning process was not planned from the beginning: it evolved in a 'learning by doing' manner over time and can retrospectively be divided into six steps (Table 1). The specific challenges for sustainability researchers were identified and developed in steps $2-4$, the roles in steps 5-6.

The sustainability researchers leading the four projects gained their experience of knowledge coproduction within the framework of an international research programme on global change. ${ }^{5}$ The criteria for selecting the projects to be analyzed were:

- Co-production of knowledge took place;

- The projects had to cope with a multi-actor situation;
- Relevant actors participated throughout the whole process of joint knowledge production;

- A criterion for the sample as a whole was that the projects should represent different socioenvironmental contexts and situations.

\section{Challenges of co-producing knowledge for sustainable development}

In the context of the debate on boundary organizations (see Figure 1), co-production of knowledge stands for 'simultaneous production of knowledge and social order' (Guston, 2001: 401). In addition to generating knowledge, boundary organizations produce social order by redrawing and stabilizing the social boundaries between academic communities and non-academic communities, such as civil society, politics, the administration or the economic sector. We share the definition of co-production as a simultaneous production of knowledge and social order. However, the crucial difference we make concerns the way in which this is done.

Instead of stabilizing the social identities that shape the boundaries between academic and nonacademic communities, sustainability research aims to produce an agora in which the boundaries are provisionally blurred; the resulting 'messiness' of 'divided identities' is the necessary condition for engaging with 'others' and ultimately helping to reshape the involved groups' 'perceptions, behaviour and agendas that occur as a function of their interaction' (Lemos and Morehouse, 2005: 61). Based on this theoretical premise, verified at the onset by the experience of the researchers involved in the four selected projects (Table 1, Steps 1-2), we identified an overall challenge for sustainability researchers: that of structuring the agora during the co-production of

Table 1. Analysing the challenges and roles of sustainability researchers: an iterative learning process involving the leaders of four concrete sustainability research projects and a scholarly discussion of co-production of knowledge

Step

Approach

1. Joint development of goal and scope of analysis

2. Auto-analysis of projects

3. First analysis of project reviews

4. Joint discussion and comparative analysis

5. Second autoanalysis of projects

6. Synthesis identity'
Intense conceptual and practice-oriented discussion (two-day workshop), leading to a common structure for Step 2

Individual analysis and writing. Research question: 'How does dialogue between thought collectives enable research for sustainability?'

Individual analysis and writing. Research question: 'What are the specific challenges for researchers involved in knowledge co-production?'

One-day intense discussion; development of the concept of 'roles' of the researcher in a knowledge co-production process in which the researcher experiences a 'divided

Individual analysis and writing. Research question: 'How were the challenges met by the researchers? What roles did they assume to enable dialogue between the thought collectives?'

Intense discussions on the validity and reach of findings, and collective writing and review of present article
Research groups involved

$A$ and $B$

B

A

$A$ and $B$

B

$A$ and $B$

Notes: $\quad$ Group A: researchers experienced in science studies

Group B: researchers conducting the analysed projects of sustainability research 
knowledge. In our auto-analysis of the projects (Steps 2-4) we distinguished three different subchallenges to be addressed by researchers: power, integration and sustainability (Table 2).

\section{The challenge of power}

The first challenge in structuring the agora is the issue of power. We understand power as the capacity of individuals or institutions to achieve their goals even if opposed by others (DeWitt, 2000). In the context of our study, having power means having the ability and the resources to negotiate and adapt interests during the process of knowledge co-production. With regard to power, the challenge for sustainability researchers is to prevent the process from being 'highjacked by local elites, companies or government agencies' (Wiggins et al., 2004: 1952), which can happen when one of the scientific disciplines or social actors involved in the co-production of knowledge imposes its perspective as the only valid one. Coproduction of knowledge requires that contributions from specific disciplines and social actors are not privileged over what other disciplines and social actors contribute (McFarlane, 2006; Dewulf et al., 2005); it also requires that communication is not seen as a one-way transfer from a knowing subject to a supposedly ignorant one (Gravois Lee and Garvin, 2003; Wynne, 1991; Freire, 1970).

To conceptualize the different actor groups and address the issue of power emerging in the knowledge co-production process, we use Ludwig Fleck's concept of 'thought collectives' that share a particular 'thought style' (Cohen and Schnelle, 1986; Fleck, 1979). Fleck introduces the concept to explain why, for example, a natural scientist and a farmer may be completely unable to understand each other and communicate, whereas the same people have no problem communicating within their own social group. According to Fleck, this is because they share a thought style, which they become acquainted with when they become a member of the corresponding social group, for example through education or training. Such a thought style includes, among others, assumptions about what aspects of an issue are relevant, how to explain them and by what specific methods an issue can be approached. The concept of 'thought style' is similar to Kuhn's (1996) concept of 'paradigm', which Kuhn developed for the realm of science based on Fleck's ideas.

A thought collective is described by Fleck as the 'carrier' of a thought style. Thought collectives are heterogeneous, as the degree of members' involvement varies. Fleck distinguishes between esoteric circles of people who produce knowledge within a thematic field, and exoteric circles of individuals who mainly receive this knowledge. Members of an esoteric circle know the producers of knowledge, often personally, and qualify its significance in a down-to earth manner, whereas members of the exoteric circle assess the same knowledge in a reverential way. Furthermore, membership in a thought collective is not exclusive. A person may be a member of more than one collective at a time, for example, he or she can be a sustainability researcher but also a Catholic and a vegetarian. Depending on the context, he or she may therefore take on different thought styles - and consequently different social roles (Stark, 2007).

We adopt Fleck's concept as used in science studies (Aeberhard and Rist, 2009; de Camargo, 2002; Fry, 2001) because it allows us, on the one hand, to characterize different social groups within and outside science primarily by their perspective on an issue, and on the other to take into account the power differential involved between the thought collectives. The concept also places the different viewpoints and expertise of the scientific disciplines and non-scientific actors involved in the knowledge coproduction process into the foreground. Such a characterization of the actors of co-production takes into account that those involved - the researchers as well as further social actors - already have distinct and relevant knowledge, and a particular perspective on an issue. Thus, the challenge of power, listed as the first in our overview (Table 2), can be related to an understanding of knowledge co-production that should ideally be based on a dialogue on equal terms between thought collectives.

\section{The challenge of integration}

The second challenge in structuring the social space for co-production of knowledge is integration. In general terms, integration means interrelating epistemological, conceptual and practical elements that

Table 2. Challenges of knowledge co-production to be addressed by sustainability researchers

Challenges

Power

Integration

Sustainability
Concrete meaning in the four case studies

Addressing power relationships between different actors

Ensuring that a common understanding emerges

Ensuring that knowledge co-production serves the purposes of 'sustainable development'
Implications for researchers (based on theory and practice)

\footnotetext{
Need to advocate the co-existence of thought collectives and thought styles and make these explicit

Need to interrelate the perspectives of the different thought collectives on the issues at stake

Need to promote the orientation towards sustainable development throughout the process of knowledge coproduction
} 


\section{The challenge for the sustainability researcher is to interrelate the thought collectives and thought styles of disciplinary research and various societal actors in relation to the issue about which knowledge is being co-produced}

were not related before (Jahn et al., 2006: 302). Integration is one of the core challenges of coproducing knowledge (Pohl et al., 2008; Jahn et al., 2006; Bammer, 2005; Van Kerkhoff, 2005; Cash et al., 2003). The challenge for the sustainability researcher is to interrelate the thought collectives and thought styles of disciplinary research and various societal actors in relation to the issue about which knowledge is being co-produced. The aim of integration in the context of sustainability research is to achieve a more comprehensive, or - in terms of power and thought styles - more balanced and adoptable understanding of an issue and corresponding solutions. Integration can stand for a stronger or weaker form of interrelation and collective agreement. In a weak reading, it means integration of interests through a joint elaboration of a boundary object (Cash et al., 2006: 470; Star and Griesemer, 1989). In a strong reading it stands for consensus achieved regarding a problem, its causes and its sustainable solution.

\section{The challenge of sustainability}

The third challenge specific to co-production of knowledge for sustainable development is related to the normative orientation of the concept of sustainable development. We understand sustainable development as 'development that meets the needs of the present without compromising the ability of future generations to meet their own needs' (World Commission on Environment and Development, 1987: 43). This definition presupposes that the world has finite resources and sinks, whose capacity to guarantee humanity's subsistence depends - among others - on technologies, modes of distribution and policies adopted to achieve greater intra- and intergenerational equity. Sustainability research ultimately aims at transforming institutions, values, practices, norms and technologies, in such a way that less finite resources and sinks are consumed and more equitable access to resources is achieved compared to the present state. In the course of their research, sustainability researchers face a number of specific challenges related to the normativeness of sustainable development (Wiesmann et al., 2008;
Hirsch Hadorn et al., 2006; Moll and Zander, 2006; Hurni and Wiesmann, 2004; Cash et al., 2003; Kates et al., 2001).

For the projects we reviewed, the normative and contested character of sustainable development was crucial, both as a starting point and a key motor of the co-production process. Sustainable development as a normative framework aims at changing social structures and practices in a particular direction. At the same time it is a contested concept: though it is well accepted in its general meaning - as in the sense quoted above - sustainable development is strongly disputed when it comes to concrete terms and implementation (Grunwald and Kopfmüller, 2006; Jacobs, 1999). The challenge for a sustainability researcher is to promote the agreed-upon orientation towards sustainable development throughout the knowledge co-production process, while simultaneously keeping in mind that the term's meaning may be repeatedly contested, requiring readjustments.

\section{Four examples of knowledge co-production}

The following section presents the four projects in which we analysed the challenges described above; we describe how the sustainability researchers addressed the three challenges in each project.

\section{Drought management in the Makueni District, Kenya} (Ifejika Speranza, 2006)

The inhabitants of Makueni District are mainly poor, with many of them living below the rural poverty line (US\$17-20 per equivalent adult person per month; 1997 factor prices) as defined for rural Kenya. Despite various endeavours, research and development efforts did not succeed in leading to sustainable drought management and food security. The research project examined here sought to improve drought management and exchange between the various thought collectives, with the aim of reducing vulnerability to drought and agro-pastoral livelihood insecurity (Ifejika Speranza et al., 2008). The thought collectives in dialogue were the agropastoral households, government and NGO workers, researchers in the area, and the Centre for Integrated Training and Research for Arid and Semi-Arid Lands Development (CETRAD), which was also the home institution of the research project. ${ }^{6}$ One of the starting points was the lack of exchange diagnosed between CETRAD's drought and drought management research on the one hand, and agro-pastoral households on the other, since the agro-pastoral households had not adapted their management practices despite concrete results from earlier research.

Power During the project's initial stages, the sustainability researchers addressed the issue of power by giving a voice to farmers. Most farmers perceived drought and its impacts as 'given by nature' and 
concluded that they could not intervene to stop drought. However, it eventually became clear that different ways of knowing about drought existed: on the one hand through long-established traditional modes of observation - that is, observing repetitions and temporal correlation of drought with other occurrences such as the rain pattern at the beginning of a season, the flowering of certain trees, the movement of bees, the noise of insects and birds, the amount of snow on the peaks of Mount Kilimanjaro, the constellation of the stars - and through information from seers and personal feelings; on the other hand, farmers supposedly also gained a different type of knowledge about drought from radio information disseminated by the Kenya Meteorological Department.

Exploring and validating farmers' knowledge about drought as a thought style helped to explain why research and the transfer of expert knowledge had had little or no influence on agro-pastoral practices. In spite of the seasonal forecasts broadcasted on the radio and the accompanying recommendations regarding the choice of drought-resistant crops and planting schedules, many farmers ignored this information and planted crop varieties that were less drought-tolerant than the ones recommended. Moreover they maintained their strong reliance on their own knowledge about drought occurrence and the corresponding mitigation strategies. The farmers explained their decisions by pointing out that past seasonal predictions on the radio had been inaccurate, and that the crop they had chosen had multiple uses. Indeed, if a maize crop does not produce cobs, at least the stalks can be used as fodder for livestock, so all is not lost. Thus, farmers relied more on their own knowledge and time-proven practices than on the advice of researchers and extension experts, because dealing with drought in their thought collective meant more than finding a drought-resistant crop.

Integration The sustainability researchers tried to interrelate the thought styles on the one hand by facilitating collective learning processes; this was achieved in the context of platforms, social networks, meetings between individuals and common workshops. Until then, some farmers had used expert advice rather selectively; now, growing trust motivated the farmers to express that they had a strong, though different, interest in science: For example, the villagers wanted to know whether it was possible to cross-breed the improved seeds of a hybrid maize variety with the local variety of Kikamba as this would better suit their livelihood needs. The farmers thus wanted the researchers to bring their findings to fruition in a project to be jointly managed by the researchers and the local communities.

On the other hand, the sustainability researchers provided results of their analysis as an input for the co-production of knowledge, even though they were only handing back information that had been collected from the agro-pastoral community itself and had later been integrated with other sources of information and knowledge about what, in the view of the researchers, actually shaped the drought problem. For the villagers, the resulting reflection about differences and similarities between their own and scientific knowledge revealed to them that they had to take a more active role in shaping the relationship between the different forms of knowledge involved.

Sustainability As the researchers' understanding of the relevance of the farmers' local knowledge increased, and vice versa, this triggered self-reflexive learning. By explicitly debating the alternatives in light of the principles of sustainability, the pros and cons of the different land use and livelihood strategies were discussed openly. Each villager present at the meetings had an opportunity to contribute his or her ideas and take home potential solutions discussed in the group. Such discussions enhanced active collective reflection among the villagers about the reasons for the vulnerability of their livelihoods and about avenues for improving livelihood security.

\section{Approaching soil protection from another angle in Switzerland (Fry, 2001)}

Swiss law requires farmers to actively avoid soil degradation caused by erosion, compaction, heavy metals and persistent organic compounds. At the level of farmers, as well as in research, extension and public administration, the step from detecting soil degradation to implementing soil protective measures has proved to be very difficult and is not really understood.

Power In a first step, by comparing the daily activities of farmers, agricultural scientists and government officers (Table 3), the sustainability researcher made the different actors' thought styles explicit to all involved.

The analysis of thought styles showed that while farmers are primarily interested in producing foodstuff and government agencies in protecting soils, soil scientists focus on producing theories about soil functions and processes. As a consequence of these aims, these three groups use different methods in different contexts. While farmers emphasize the observation of soil and plant properties during their work on the fields, focusing on the interplay of farming equipment and varying site-specific conditions, scientists focus on certain soil properties and choose representative, statistically relevant fields regardless of the practical implications the choice may have from the point of view of a farmer. The key problem, for scientists, is how to standardize and generalize their results so that experiments can be reproduced in different local contexts (Clark and Murdoch, 1997: 41). The key problems that farmers have to solve are: changing market conditions, 
Table 3. Three thought collectives' perceptions of soils and implications of these perceptions for framing action

Stakeholder

\begin{tabular}{lllll}
$\begin{array}{lll}\text { Aspect of working } \\
\text { with soils }\end{array}$ & \multicolumn{1}{c}{ Farmers } & \multicolumn{2}{c}{ Government officials } & Scientists \\
Aim & $\begin{array}{l}\text { Production (plants, } \\
\text { animals) }\end{array}$ & Soil protection (to maintain soil quality) & $\begin{array}{l}\text { Soil theory (functions, } \\
\text { processes) } \\
\text { Method }\end{array}$ \\
$\begin{array}{l}\text { Action (tillage, sowing, } \\
\text { harvesting, etc.) }\end{array}$ & Policy work & Monitoring & Monitoring \\
Perception during work & Advice; regulations & Quantification & Quantification \\
Conditions & $\begin{array}{l}\text { Heterogeneous (field, } \\
\text { weather, seasons, etc.) }\end{array}$ & Heterogeneous (field) & Standard (laboratory) & Controlled (laboratory) \\
Site & Farmland & Eroded sites & Investigated sites & Plots examined \\
Timeframe & Lifetime & In case of suspicion & Five to 10 years & Several years per project
\end{tabular}

Note: cf. Fry (2001: 65)

finding out what crops to grow, and knowing when the right time has come to sow or harvest and what machines are suitable.

Governmental officials are situated somewhere in between these two thought collectives. They aim at protecting the soil mainly by relying on natural science investigations conducted under standardized conditions. Although each actor group has the same power to act, government officers and scientists have greater symbolic and political power than farmers, who therefore tend to distrust the sciencebased norms and rules, which they perceive as coming 'from above'. The distinction between thought collectives in Table 3 helped to explain the communication problems that emerged when scientific knowledge was translated into farming practices.

Integration Within the project, intermediaries accomplished integration. In a first step, the sustainability researcher moved between the scientific, administrative and farmers' thought collectives in order to relate the different thought styles. She was acquainted with the three thought styles through her previous work. Based on her intermediary work, a project entitled 'From Farmer to Farmer' was launched. Farmers with experience in soil conservation were filmed, aiming for an audience of farmers. Personal relationships and the resulting trust and credibility as well as the bridge-building concept convinced the actors in soil protection and agriculture to engage in the project.

In a second step, farmers were interviewed and filmed by the sustainability researcher's team. The farmers were chosen because they were also intermediaries between science and practice. Most of them had worked with scientists and soil protection agencies in the past and had introduced and developed soil-conserving methods with the agencies over several years. During this process of knowledge exchange they developed valuable implementation know-how. This know-how was made explicit and thus became communicable by means of qualitative research and video filming. The joint elaboration of the documentary film was a central part of the project and made it possible to take into account the aims, methods and contexts of farmers' work, as well as their manner of communicating and their communication channels.

Sustainability In order to promote an orientation towards sustainable development in the various communication processes, the sustainability researcher facilitated regular meetings with all the actors directly involved in the project to discuss the steps and contents to be considered in the film. During these meetings, between farmers, experts, researchers and policy-makers, a great deal of knowledge was exchanged. The insights expressed and knowledge demonstrated concerning soilconserving agriculture were also submitted to reflection and summarized by this multi-stakeholder backstopping group. The emerging knowledge had to become credible for scientists, soil protection agencies, agricultural experts and practitioners alike, implying a related joint adaptation of values and norms regarding sustainable soil protection and agriculture.

\section{Governance of biodiversity in Tunari National Park, Bolivia (Boillat, 2007)}

The launching of a research project in Tunari National Park in Bolivia was related to a conflict between the indigenous peasants who inhabited park areas and the central government who wanted to implement a conservation plan. The controversy evolved around the question: 'Who should define the use of resources in Tunari National Park?' While farmers emphasized their right to use the natural resources enclosed in the park, the state focused on guaranteeing the ecosystem functions of the area: provision of water resources; prevention of floods; 'green lung', source of recreation and tourism; and conservation of biodiversity. The thought collectives involved were the central government, the indigenous Quechua communities and the researchers. 
Power By discussing the issues at stake with both the indigenous and governmental thought collectives and by systematizing results, the sustainability researchers succeeded in replacing the focus on power with a focus on the differences between worldviews. It was shown that the government authorities based their proposal on a scientificconservationist view: they wanted to promote conservation of the area through legal norms that implied severe restrictions to agriculture, livestock keeping and agro-forestry. The farmers on the other hand managed their land based on traditional Andean concepts which define soil, plants, animals and humans as part of a 'living community' closely interacting with Pachamama ('Earth's mother') as main deity. For example, chaqra is the cultivated field, sumpi is fallow-land and puruma is 'virgin' land that is not cultivated. Sumpi and puruma are grazing land. While the short-term cultivationfallow cycle relates chaqra and sumpi, puruma belongs to a long-term cycle in which it is associated with cultivated land since (pre-colonial) Inca times and may be cultivated again. Within puruma, the presence of spiritual beings (ancestors and Pachamama) is much stronger. Landscape management is conceived by the farmers as mutual nurturing of all living elements, with a dialogue between them: 'here are the plants, birds, winds, clouds, stars and the sun, they all tell us when it is time to sow' (farmer's testimony).

The researchers also demonstrated that the peasants' land use system was very efficient in maintaining ecosystem diversity in the park area, and that the presence of local actors was not the problem but the solution when biodiversity was at stake. This clearly helped to improve the position of farmers in the negotiation process with governmental and conservationist organizations involved in discussing the future of the park.

Integration The sustainability researchers integrated the thought collectives in two ways. First the project facilitated a dialogue by offering a public space (platform) for the conflicting parties. Since research was carried out by the Agroecology Programme of the University of Cochabamba (AGRUCO), which is part of the public Universidad Mayor de San Simon, the peasants and the governmental stakeholders had an opportunity to meet outside the usually conflictridden arenas. Second, the researchers provided scientific arguments for a shared use of the park. Initial participatory research results had shown that biodiversity - and thus the functions of oxygen production, groundwater recharge, recreation, tourism, and risk prevention - depend directly on the presence of indigenous communities. By pointing out the positive contribution of local actors' knowledge to the purposes for which the park had been established, the researchers initiated a process that created new conditions for the integration of different thought styles on a more equal basis.

\section{The peasants' land use system was very efficient in maintaining ecosystem diversity in the park area, and the presence of local actors was not the problem but the solution when biodiversity was at stake}

Sustainability The discussion between the two thought collectives led to an agreement that the basic assumptions, on which the park management project had been developed so far, needed to be reformulated. The ideas emerging from the researchers' discussions with almost all of the communities affected by the park motivated the leaders of social movements to propose a re-categorization of the park as an 'Area of Integrated Development'. In return for receiving support for 'respecting their cultural and historic patrimony' (i.e. improved educational, health, infrastructural and economic conditions in the area), the local stakeholders were prepared to revitalize their traditional forms of natural resource use in a way that would contribute to improving the park's ecological and recreational functions. Thus, the challenge of promoting sustainable development was addressed in this case by facilitating a collective learning process.

\section{Conservation and livelihood interests in Kangchen- junga Conservation Area, Nepal (Gurung, 2006)}

Kangchenjunga Conservation Area is situated in northeastern Nepal and shares an international border with India in the east and China in the north. In recognition of its rich natural and cultural resources, the Kangchenjunga area was declared a 'Gift to the Earth' in support of WWF's Living Planet Campaign, and officially conferred a protected area status by His Majesty's Government of Nepal in 1997. This was done after very limited consultation of local inhabitants, creating contradictions between conservation and development needs. In 1998 the Kangchenjunga Conservation Area Project (KCAP) was launched with the aim:

to safeguard biodiversity of the area and improve the living conditions of the local residents by strengthening capacity of local institutions responsible for making decisions which will effect long-term viability of genetic conservation and economic development of the area. (WWF-NP/KCAP, 1998: 4)

The aim of the research project was to reconsider the KCAP in order to explore more efficient ways of 
reconciling conservation and livelihood interests. The thought collectives involved were: representatives of community-based organizations: local women and men whose livelihoods were directly impacted on by conservation policies and project activities; the local government, the Ministry of Forest and Soil Conservation/Department of National Parks and Wildlife Conservation, legally responsible for managing protected areas and formulating policies; non-governmental organizations such as WWF; and the sustainability researcher.

Power In a first step the sustainability researcher analysed the relation between conservation and livelihood needs, giving equal attention to the interests of the two main thought collectives involved. As in the Tunari Park, results indicated that much of the faunal and floral diversity found in the area were living proofs of the co-existence of nature and human beings. Highlighting the importance of local people's management of natural resources for maintaining the value of the protected area was understood also as creating more equal conditions for the knowledge dialogue. However, it was also concluded that conservation and livelihood goals did not always go hand in hand: while the increasing presence of snow leopards and other wild animals in the area was seen as a success by conservationists, local inhabitants perceived this as a threat to their livelihoods because it meant suffering losses of crops and livestock.

Farmers' complaints regarding the losses due to wild animals were taken as seriously as the conservation requirements for survival of the snow leopard population; this was crucial for overcoming the fundamental conflict between conservation and development. This required a previous acknowledgement of the fact that imposing a protected area through an alliance between conservationists and public administration was unjust.

Integration and sustainability Within the framework of the project the sustainability researcher developed and realized a community-managed insurance scheme to cover yak loss caused by snow leopards. The integrative challenge that the insurance had to meet was to cover the conservationists' as well as the inhabitants' interests. Integration of both thought collectives' views was thus possible by explicitly pricing the value of wildlife and of the livestock losses caused. The mechanism the scheme proposed now compensates the financial loss of yaks - thus preventing farmers from hunting snow leopards - and at the same time sets an incentive to protect the yaks. The scheme includes a communitybased verification mechanism, which entails that the already well-established Snow Leopard Conservation Committee verifies individual claims before compensation is given. It is expected that this will mitigate some of the inherent risks associated with insurances, such as fraudulent claims.
The sustainability researcher used his knowledge of snow leopards and his understanding of the concerns, values, institutions and norms of the different thought collectives to propose a solution that related their perspectives to one another, in the sense of balancing their respective interests. In doing so, the researcher also promoted the orientation towards sustainable development.

\section{Discussion}

In the four projects, the academic and non-academic communities confronted one another's worldviews in a purposefully open intellectual and social space, the agora. How did the co-production of knowledge develop successfully despite the resulting indeterminacy of meaning, norms and understanding? And what role did the researchers assume in this social space? In our auto-analysis of the projects (Table 1, Steps 5-6), we found that the sustainability researchers reflected in a first step on their 'divided identity' (Ravetz, 2001) as academics and practitioners from the very beginning of their research. However, rather than feeling incapacitated by this divided identity, they used it to strengthen the research process, which was fundamentally conceived as a transdisciplinary one (Hirsch Hadorn et al., 2008). Their awareness of the social role that corresponded to each identity and their growing understanding of the thought styles and norms related to these roles (Stark, 2007), made it possible for them to assume different roles more consciously and more purposefully at different stages of the knowledge coproduction process.

In the four cases described above, the researchers gave up the authority associated with their role as Mode 1 academics, in order to be able to ensure successful transition to Mode 2 knowledge coproduction. They assumed roles as reflective scientist, intermediary and facilitator (Table 4), which allowed them to meet the three challenges of power, integration and sustainability (Table 2) in the specific contexts of their research. The role of the reflective scientist is to provide scientific expertise, validated either as 'objective' or 'intersubjective' by the discipline involved. The role of the intermediary is to mediate between the different thought styles to which one has access. Finally, the role of the facilitator is to help the thought collectives meet the challenges in a manner oriented towards openness and deliberation by initiating a collective learning process.

Table 5 summarizes the roles in which the sustainability researchers addressed the three identified challenges in each project. As Table 5 indicates, in all four projects the sustainability researchers addressed the challenge of power in the role of the reflective scientist. The scientists made the existence of thought collectives explicit to all actors involved, for example by juxtaposing the thought styles as 
Table 4. Three basic roles through which sustainability researchers met the challenges of knowledge co-production (power, integration and sustainability)

\begin{tabular}{ll} 
Role & \multicolumn{1}{c}{ Expectations } \\
Reflective scientist & $\begin{array}{l}\text { Capable of providing expertise based on scientific } \\
\text { knowledge validated according to the norms of the } \\
\text { natural or social sciences }\end{array}$ \\
Intermediary & $\begin{array}{l}\text { Able to make different thought styles visible and to link } \\
\text { them around common interests } \\
\text { Facilitator }\end{array}$ \\
$\begin{array}{l}\text { Capable of enhancing communicative processes } \\
\text { between thought collectives, based on respect, } \\
\text { openness and deliberation }\end{array}$
\end{tabular}

Norms

Validate knowledge according to quantitative and qualitative procedures

Provide leadership in view of representing common interests

Promote joint reflection oriented towards a common understanding of situations and collective action, as part of a learning process alternative perspectives on the issues at stake. By dealing with and presenting the thought collectives as alternatives — hence as equally valid and useful, but serving different interests — the sustainability researchers created the conditions for a dialogue on more equal terms. The revealing of power relations was not achieved by addressing the relations between local and external thought collectives in terms of power; it was achieved by providing expertise on the different thought styles and by highlighting the value, relevance and possible complementarity of each perspective. This is also what implicitly led participants to attribute neutrality to the role of reflective scientist.

In the case of soil protection, the sustainability researchers addressed the challenges of integration and sustainability mainly in the role of the intermediary. The intermediary meets the challenges as someone who both knows how each thought collective addresses the issues at stake and helps to search for solutions suitable to each of them. Different persons may be in the role of the intermediary. In the Swiss project the role was assumed by the sustainability researcher when she interrelated the institutions' perspective with the views of scientists and practitioners, as well as with the views of innovative farmers who worked with the public agencies in charge of developing and implementing appropriate institutional support for the dissemination of soil conservation technologies.
In the Bolivian, Kenyan and Swiss cases the sustainability researcher also took on a facilitating role. The facilitator helps the thought collectives to meet the challenges of knowledge co-production without engaging directly in the contents of discussions but instead, by facilitating a learning process. The role of the facilitator can, but need not be, assumed by the sustainability researcher.

The review of the four projects suggests that, in order for co-production of knowledge for sustainable development to be successful, the challenge of power should be addressed by sustainability researchers as reflective scientists, whereas the challenges of integration and sustainability can be addressed by the sustainability researchers as reflective scientist, or by the sustainability researcher and other actors as intermediaries or facilitators of a learning process.

A further common feature of the four projects is that the challenges were met within a public space, resulting from the embedding of the individual research projects (PhDs) in organizations directly involved in public debates and activities (three NGOs and one university department with formal interfaces with civil society and governmental institutions). These public spaces seemed to function as agoras open for the initial indeterminacy of the knowledge coproduction situation and its potential restructuring.

Whereas Table 5 indicates that the challenge of power seems best met in the role of the reflective

Table 5. Roles in which challenges were met by the sustainability researchers in the four projects examined

\section{Project}

Challenge of knowledge co-production in sustainability research

(a) Addressing power relations by making thought collectives and their relationships explicit

(b) Integrating different thought styles

(c) Maintaining the orientation towards sustainability

\begin{tabular}{|c|c|c|c|}
\hline $\begin{array}{c}\text { Makueni District, } \\
\text { Kenya } \\
\text { Role: }\end{array}$ & $\begin{array}{l}\text { Soil protection, } \\
\text { Switzerland } \\
\text { Role: }\end{array}$ & $\begin{array}{c}\text { Tunari National } \\
\text { Park, Bolivia } \\
\text { Role: }\end{array}$ & $\begin{array}{c}\text { Kanchenjunga } \\
\text { Conservation Area, } \\
\text { Nepal } \\
\text { Role: }\end{array}$ \\
\hline Reflective scientist & Reflective scientist & Reflective scientist & Reflective scientist \\
\hline $\begin{array}{l}\text { Facilitator } \\
\text { (Reflective scientist) }\end{array}$ & Intermediary & Facilitator & Reflective scientist \\
\hline Facilitator & $\begin{array}{l}\text { Intermediary } \\
\text { (Facilitator) }\end{array}$ & Facilitator & Reflective scientist \\
\hline
\end{tabular}


scientist, it does not give clear indications for the challenges of integration and sustainability. A factor that we did not analyse systematically, but which might be relevant in relation to tackling the challenges of integration and sustainability, is the social process that emerges from such work. In the Bolivian and Kenyan cases, the farmers soon took over the leading role in the learning and negotiation processes. As a consequence, the sustainability researchers changed their role to that of facilitators. In the case of Switzerland, the researcher first had to assume the role of an intermediary, as a precondition for facilitation. In the case of Nepal, the participating local residents decided to ask the researcher to propose a solution that was discussed and negotiated only at a later stage of the processes; consequently, the role of reflective scientist was used to meet all three challenges of knowledge co-production.

Why did the sustainability researchers assume different roles to address the challenges of integration and sustainability, while they all addressed the challenge of power as reflective scientists? The role of reflective scientist was adequate to address the challenge of power in all four cases mainly because it allowed the researchers to present credible data about the thought styles available and the hierarchical relationship between the different thought collectives, thus empowering all non-scientific actors as knowledge contributors. Moreover, science played the role of independent and socially respected observers suggesting possible changes in the way that thought collectives might interrelate. Power relations were not blamed as such but were made visible as an obstacle to achieving better collaboration and moving towards more sustainable solutions.

Our analysis of the challenges of integration and orientation toward sustainability shows that the researchers succeeded in shifting roles from the role of scientist to that of intermediary or facilitator in those cases where the non-academic actors no longer attributed sole validity to the scientific thought style. Attribution of authority to science over other thought styles was an implicit process in all cases. As the degree of authority implicitly attributed to science was comparatively low in the Kenyan and Bolivian cases, the researchers had no problem in taking up the role of facilitator, thus gradually concentrating more on moderating the collective learning process and helping to find solutions to obstacles identified as impeding better co-production of knowledge.

The higher degree of implicit authority attributed to science in the Swiss case made it necessary for the researcher to maintain the implicitness of the knowledge co-production process while making more visible what interests the thought collectives had in common, and what potential each thought collective could contribute in the search for more sustainable ways of dealing with soil erosion. In the Nepalese case the degree of implicit authority attributed to science was comparatively the highest; the thought collectives asked the researcher to propose a way of integrating their thought styles in view of sustainability. As a consequence the researcher remained in the role of the scientist to face all three challenges.

\section{Conclusions and recommendations}

Current discussions on boundary organizations suggest that co-production of knowledge is effective if it provides credible, salient and legitimate information (Cash et al., 2003). The challenges (Table 2) and roles (Table 4) described in the present article are on the one hand specifications and translations of these requirements from the perspective of a sustainability researcher involved in and responsible for a project that aims at co-production at the local level. On the other hand the challenges and roles point to intellectually as well as socially demanding new tasks that emerge from requirements such as credibility and legitimacy when knowledge co-production follows a Mode 2 process.

For example, when bringing disciplinary researchers and non-academic actors together, it may be that credibility (scientific adequacy) and legitimacy (respect for all stakeholders' diverging values and beliefs) become incompatible goals:

- What if non-academic actors' views conflict with the researcher's view of what the problem is and what kind of development is required for moving towards greater sustainability?

- How can this conflict be made explicit in order to deal with it productively?

- Moreover, how can different actors' thought styles be integrated in such a situation, while at the same time promoting the agreed-upon orientation towards sustainable development?

- What skills do researchers need to assume different roles depending on the challenge to be met, in particular the roles of reflective scientist, intermediary and facilitator of a learning process?

Our analysis provides a range of possible answers to these questions.

The sustainability researchers in the four projects we analysed handled the challenges and chose the various roles assumed intuitively; it is likely that they succeeded because each researcher had worked as a practitioner at some point in the past. They relied on learning by doing rather than on a systematic analysis, choice of role and use of method, and on a rather intuitive orientation based on an equally rather implicit understanding of a collective learning process. What our analysis shows is that the intuitive assuming of specific roles seemed to be clearly guided by the objective of promoting and enhancing knowledge coproduction, based on openness and the search for deliberative interaction of all the thought collectives involved. These insights allow us to identify 
The sustainability researchers

handled the challenges and chose the various roles assumed intuitively; it is likely that they succeeded because each researcher had worked as a practitioner at some point in the past

possible ways of enhancing training of sustainability researchers. We propose that such training be included and enhanced in curricula for higher education in the field of sustainable development. Such training should cover the theoretical background for, and offer practical exercises in:

- A pluralist understanding of cognition and interpretation of the world, such as the idea of coexisting thought collectives. To make the different thought collectives' perspectives explicit and understandable to all, it is necessary to be or become familiar with them, either by developing personal relationships with their members or by being part of them for a certain time and being able to reflect on differences and similarities. Anthropological, ethnological and qualitative methods and theories, developed to explore others' unknown viewpoints, are often used to this purpose, however so far without being an explicit part of training and/or communication between all the actors involved in sustainable development projects.

- Sensitivity to underlying power relations between, as well as within, thought collectives. Knowledge of how power issues can influence participation as well as the search for ways and means to diminish their inhibiting influence are therefore further crucial competences.

- Skills in integration of different interests, different thought collectives, and corresponding practices, values and interpretations in search of more sustainable solutions.

- Skills in facilitating collective learning processes, such as organizing meetings of an appropriate kind, offering a space where people can meet beyond established hierarchies and social and cultural boundaries, building trust between the parties involved, enabling self-reflexivity among the different thought collectives, and facilitating exchange among them about the issues at stake and the different perceptions they have of the issues. Moreover, to train and backstop these groups, special knowledge and experience is needed, for example in managing conflicts and enabling collective learning processes.

\section{Acknowledgements}

The research for this article was supported by the Swiss National Centre of Competence in Research (NCCR) North-South: Research Partnerships for Mitigating Syndromes of Global Change, co-funded by the Swiss National Science Foundation (SNSF), the Swiss Agency for Development and Cooperation (SDC) and the participating institutions. Further support was provided by the Swiss National Science Foundation's project, 'Structuring the science-policy nexus in sustainability research'. The authors would like to thank two anonymous reviewers and the editor for their very useful and insightful comments.

\section{Notes}

1. See <http://www.unep.org/Documents.Multilingual/Default.asp ?DocumentID=52>

2. According to Stark (2007) a social role is defined by '[a] set of expectations that govern the behaviour of persons holding a particular position in society; a set of norms that defines how persons in a particular position should behave'.

3. Not only the researchers, but also the non-scientific actors may find themselves in a situation of divided identity in coproduction of knowledge. The aim of the present article is however to discuss how the researchers are challenged by this situation.

4. A critical debate about Mode 2 types of knowledge production is currently being conducted in the literature (for a review of the discussion see Hessels and Van Lente, 2008). Interestingly, the discussion and analysis of Mode 2 often follows a Mode 1 approach. This is the case if a critical analysis questions the lack of 'reliability' and 'universal and context-free knowledge' of Mode 2 knowledge production (Hessels and Van Lente, 2008; Crompton, 2007; Pestre. 2000; Weingart 1997), since these criteria are typical features used to validate Mode 1 knowledge production. Although we agree with Hessels and Van Lente (2008) that the Mode 2 concept needs to be unpacked and approached critically, we prefer to use this term rather than coining a new one, as it is now well-known in the research policy debate. We use the dichotomy between Mode 1 and Mode 2 argumentatively in the sense of 'ideal types', as indicated by Hessels and Van Lente (2008: 757).

5. This common program is the Swiss National Centre of Competence in Research (NCCR) North-South. See <http://www. north-south.unibe.ch/>.

6. CETRAD carries out academic research and translates findings in the form of development projects.

\section{References}

Aeberhard, A and S Rist 2009. Transdisciplinary co-production of knowledge in the development of organic agriculture. Ecological Economics, 68, 1171-1181.

Agrawala, S, K Broad and D H Guston 2001. Integrating climate forecast and societal decision making: challenges to an emergent boundary organization. Science, Technology and Human Values, 26(4), 454-477.

Anderson, L 2006. Analytic autoethnography. Journal of Contemporary Ethnography, 35(4), 373-395.

Bammer, G 2005. Integration and implementation sciences: building a new specialization. Ecology and Society, 10(2).

Becker, E 2003. Transformations of social and ecological issues into transdisciplinary research. In Encyclopedia of Life Support Systems (EOLSS), UNESCO and EOLSS Publishers. Paris: UNESCO.

Boillat, S 2007. Traditional ecological knowledge, land use and ecosystem diversity in the Tunari National Park (Bolivia). An ethnoecological approach for dialogue between traditional and scientific ecological knowledge. PhD thesis. Centre for Development and Environment, Institute of Geography of the University of Bern; Faculty of Sciences. Bern: University of Bern.

Cash, D W, W C Clark, F Alcock, N M Dickson, N Eckley, D H Guston, J Jäger and R B Mitchell 2003. Knowledge systems for sustainable development. Proceedings of the National 
Academy of Sciences, 100(14), 8086-8091.

Cash, D W, J C Borck and A G Patt 2006. Countering the loadingdock approach to linking science and decision making. Science, Technology and Human Values, 31(4), 465-494.

Clark, T J, and J Murdoch 1997. Local knowledge and the precarious extension of scientific networks: a reflection on three case studies. Sociologia Ruralis, 37, 38-60.

Cohen, R S and T Schnelle eds. 1986. Cognition and Fact: Materials on Ludwik Fleck. Dordrecht a.o.: Reidel.

Crompton, H 2007. Mode 2 knowledge production: evidence from orphan drug networks. Science and Public Policy, 34(4), 199-211.

Cundill, G, C Fabricius and N Marti 2005. Foghorns to the future: using knowledge and transdisciplinarity to navigate complex systems. Ecology and Society, 10(8) [online].

Dahdouh-Guebas, F, J Ahimbisibwe, R V Moll and N Koedam 2003. Neo-colonial science by the most industrialised upon the least developed countries in peer-reviewed publishing. Scientometrics, 56, 329-343.

De Camargo, K R 2002. The thought style of physicians: strategies for keeping up with medical knowledge. Social Studies of Science, 32, 827-855.

DeWitt, M R 2000. Beyond Equilibrium Theory: Theories of Social Action and Social Change Applied to a Study of Power Sharing in Transition. Lanham, MD: University Press of America.

Dewulf, A, M Craps, R Bouwen, F Abril and M Zhingri 2005. How indigenous farmers and university engineers create actionable knowledge for sustainable irrigation. Action Research, 3(2), 175-192.

Elden, $M$ and $M$ Levin 1991. Cogenerative learning: bringing participation into action research. In Participatory action research, ed. W F Whyte, pp.127-142. Newbury Park: Sage Publications.

Fleck, L 1979. Genesis and Development of a Scientific Fact. Chicago/London: University of Chicago Press.

Freire, P 1970. Pedagogy of the Oppressed. New York: Seabury.

Fry, P 2001. Bodenfruchtbarkeit: Bauernsicht und Forscherblick. Weikersheim: Margraf Verlag.

Funtowicz, S, I Shepherd, D Wilkinson and J Ravetz 2000. Science and governance in the European Union: a contribution to the debate. Science and Public Policy, 27(5), October, 327-336.

Gibbons, M, C Limoges, H Nowotny, S Schwartzman, P Scott and M Trow 1994. The New Production of Knowledge: the Dynamics of Science and Research in Contemporary Societies. London/Thousand Oaks/New Delhi: Sage.

Gravois Lee, R and T Garvin 2003. Moving from information transfer to information exchange in health and health care. Social Science and Medicine, 56, 449-464.

Grunwald, A and J Kopfmüller 2006. Nachhaltigkeit. Frankfurt/New York: Campus.

Guggenheim, M 2006. Undisciplined research: the proceduralisation of quality control in transdisciplinary projects. Science and Public Policy, 33(6), July, 411-421.

Gurung, G S 2006. Reconciling Biodiversity Conservation Priorities with Livelihood Needs in Kangchenjunga Conservation Area, Nepal. PhD thesis. Zurich: University of Zurich.

Guston, D H 1999. Stabilizing the boundary between US politics and science: the rôle of the office of technology transfer as a boundary organization. Social Studies of Science, 29(1), 87-111.

Guston, D H 2001. Boundary organizations in environmental policy and science: an introduction. Science, Technology and Human Values, 26(4), 399-408.

Hessels, L and $H$ van Lente 2008. Re-thinking new knowledge production: a literature review and a research agenda. Research Policy, 37, 740-760.

Hirsch Hadorn, G, D Bradley, C Pohl, S Rist and U Wiesmann 2006. Implications of transdisciplinarity for sustainability research. Ecological Economics, 60, 119-128.

Hirsch Hadorn, G, H Hoffmann-Riem, S Biber-Klemm, W Grossenbacher-Mansuy, D Joye, C Pohl, U Wiesmann and E Zemp eds 2008. Handbook of Transdisciplinary Research. Dordrecht: Springer.

Hurni, $\mathrm{H}$ and $\mathrm{U}$ Wiesmann 2004. Towards transdisciplinarity in sustainability-oriented research for development. In Research for Mitigating Syndromes of Global Change: a Transdisciplinary Appraisal of Selected Regions of the World to Prepare Development-Oriented Research Partnerships, eds H Hurni, U Wiesmann and R Schertenleib, pp. 31-41. Bern: University of Bern.
Ifejika Speranza, C 2006. Drought Vulnerability and Risk in AgroPastoral Areas: an Integrative Approach and its Application in Kenya. PhD Thesis. Centre for Development and Environment, Institute of Geography, University of Bern, Switzerland.

Ifejika Speranza, C, B Kiteme and U Wiesmann 2008. Droughts and famines: the underlying factors and the causal links among agro-pastoral households in semi-arid Makueni district, Kenya. Global Environmental Change, 18(1), 220-233.

Jacobs, M 1999. Sustainable development as a contested concept. In Fairness and Futurity, ed. A Dobson, pp. 21-45. Oxford: Oxford University Press.

Jahn, T, F Keil and E Schramm 2006. Transdisziplinäre Integration. In Soziale Ökologie - Grundzüge einer Wissenschaft von den gesellschaftlichen Naturverhältnissen, eds E Becker and T Jahn, pp. 287-339. Frankfurt/New York: Campus.

Kasemir, B, J Jäger, C C Jaeger and M T Gardner, eds 2003. Public Participation in Sustainability Science. Cambridge: Cambridge University Press.

Kates, R W, W C Clark, R Corell et al. 2001. Sustainability Science. Science, 292, 641-642.

Klein, J T, W Grossenbacher-Mansuy, R Häberli, A Bill, R W Scholz and M Welti eds. 2001. Transdisciplinarity: Joint Problem Solving among Science, Technology, and Society. Synthesebücher, Basel: Birkhäuser Verlag.

Kuhn, T 1996. The Structure of Scientific Revolutions. Chicago: University of Chicago Press.

Lawrence, R and C Després 2004. Futures of transdisciplinarity. Futures, 36, 397-405.

Lemos, M C and B J Morehouse 2005. The co-production of science and policy in integrated assessments. Global Environmental Change, 15, 57-68.

Lewenstein, B V 2002. Editorial: a decade of public understanding. Public Understanding of Science, 11, 1-4.

Maasen, S and O Lieven 2006. Transdisciplinarity: a new mode of governing science? Science and Public Policy, 33(6), July, 399-410.

McFarlane, C 2006. Crossing borders: development, learning and the North-South divide. Third World Quarterly, 27(8), 14131437.

Moll, $\mathrm{P}$ and $\mathrm{U}$ Zander 2006. Managing the Interface: from Knowledge to Action in Global Change and Sustainability Science. Munich: Oekom.

Nowotny, H, P Scott and M Gibbons 2001. Re-Thinking Science: Knowledge and the Public in an Age of Uncertainty. Cambridge: Polity Press.

Owens, S, T Rayner and B Olivia 2004. New agendas for appraisal: reflections on theory, practice and research. Environment and Planning A, 36, 1943-1959.

Pestre, D 2000. The production of knowledge between academies and markets: a historical reading of the book The New Production of Knowledge. Science, Technology and Society, 5, 169181.

Pohl, C, L van Kerkhoff, G Bammer and G Hirsch Hadorn 2008. Integration. In Handbook of Transdisciplinary Research, eds $\mathrm{G}$ Hirsch Hadorn, H Hoffmann-Riem, S Biber-Klemm et al., pp. 411-424. Dordrecht: Springer.

Pregernig, M 2006. Transdisciplinarity viewed from afar: sciencepolicy assessments as forums for the creation of transdisciplinary knowledge. Science and Public Policy, 33(6), July, 445-455.

Ravetz, J 2001. Science advice in the knowledge economy. Science and Public Policy, 28(5), October, 389-393.

Rist, S, M Chiddambaranathan, C Escobar and U Wiesmann 2006. 'It was hard to come to mutual understanding': the multidimensionality of social learning processes concerned with sustainable natural resource use in India, Africa and Latin America. Systematic Practice and Action Research, 19, 219-237.

Robinson, J and J Tansey 2006. Co-production, emergent properties and strong interactive social research: the Georgia Basin Futures Project. Science and Public Policy, 33(2), March, $151-160$.

Star, S L and J R Griesemer 1989. Institutional ecology, 'translations' and boundary objects: amateurs and professionals in Berkeley's Museum of Vertebrate Zoology, 1907-1939. Social Studies of Science, 19, 387-420.

Stark, R 2007. Sociology, 10th edn. Thomson Wadsworth, CA: Baylor University.

Strauss, A and J Corbin 1990. Basics of Qualitative Research: Grounded Theory, Procedures and Techniques. Newbury Park: Sage. 
Van Kerkhoff, L 2005. Integrated research: concepts of connection in environmental science and policy. Environmental Science and Policy, 8, 452-463.

Weingart, P 1997. From 'finalization' to 'Mode 2": old wine in new bottles? Social Science Information, 36, 591-613.

Wiesmann, U, S Biber-Klemm, W Grossenbacher-Mansuy, Hirsch Hadorn, G, H Hoffmann-Riem, D Joye, C Pohl, and E Zemp 2008. Enhancing transdisciplinary research: a synthesis in fifteen propositions. In Handbook of Transdisciplinary Re search, eds $\mathrm{G}$ Hirsch Hadorn, H Hoffmann-Riem, S BiberKlemm et al., pp. 433-441. Dordrecht: Springer.
Wiggins, S, K Marfo and $\mathrm{V}$ Anchirinah 2004. Protecting the forest or the people? Environmental policies and livelihoods in the forest margins of Southern Ghana. World Development, 32(11), 1939-1955.

World Commission on Environment and Development 1987. Our Common Future. Oxford: Oxford University Press.

WWF-NP/KCAP 1998. Kangchenjunga Conservation Area Project: Annual Technical Project Progress Report: July 01, 1997June 30, 1998. Kathmandu: WWF Nepal Program.

Wynne, B 1991. Knowledges in context. Science, Technology, and Human Values, 16(1), 111-121. 